\title{
Income comparisons and non-cognitive skills
}

\author{
Santi Budria \\ Universidade de Madeira, CEEAplA \& IZA \\ and \\ Ada Ferrer-i-Carbonell \\ Institut d'Anàlisi Econòmica (CSIC), Barcelona GSE \& IZA
}

April 2012

\begin{abstract}
People gain utility from occupying a higher ranked position in the income distribution of the reference group. This paper investigates whether these gains depend on an individual's set of non-cognitive skills. Using the 2000-2008 waves of the German Socioeconomic Panel dataset (SOEP), a subjective question on Life Satisfaction, and three different sets of non-cognitive skills indicators, we find significant and robust differences across skills groups. People who are more neurotic, extravert and have low external locus of control and low negative reciprocity are more sensitive to their individual position in the economic ladder. By contrast, the Life Satisfaction reaction to changes in economic status is significantly lower among individuals who score high (low) in negative (positive) reciprocity, and are at the bottom of the distribution of neuroticism, extraversion. The heterogeneity on the importance of income comparisons needs to be taken into account when, for example, introducing them into economic models, predicting individuals' behaviour, or making welfare judgments.
\end{abstract}

Keywords: Life satisfaction; income comparisons; personality traits.

JEL codes: D62; I31

\section{Contact author:}

Santi Budria

Departamento de Gestão e Economia

Rua Penteada 9000-360 Funchal (Portugal)

E-mail: sbudria@uma.pt 


\section{Introduction}

Individuals are rank sensitive: they care about how well they perform in comparison with the relevant others. In economics and other disciplines, there has been an important set of literature devoted to understanding how individuals are influenced by their reference groups and who their reference group is. In economics, the distinction between absolute and relative formulations of utility has proven a useful concept to rationalize a large set of unexplained phenomena in a variety of fields, including asset pricing (Campbell and Cochrane, 1999, Abel, 2008), growth (Carroll at al., 2000), consumption behavior (Fuhrer, 2000) and wealth inequality (Díaz et al., 2003). Advances at the theoretical level have been parallel to a new wave of empirical papers assessing the relative importance of relative effects for individuals' utility or welfare. Many of these papers are based on the use of self-reported happiness or life satisfaction as a proxy for individual utility. The empirical evidence is clear: people gain utility from occupying a higher ranked position in the income distribution of the reference group (Brown et al., 2008; Clark et al., 2009a; Powdthavee, 2009; Boyce, 2010a).

This paper examines whether the rank effect differs between individuals endowed with different sets of non-cognitive skills and finds a large heterogeneity on the importance of income comparisons. The paper uses the 2000-2008 waves of the German Socio-economic Panel dataset (SOEP) and three different sets of non-cognitive skills indicators. The first set refers to the Big Five Inventory, a model that represents a widely accepted approach to conceptualizing personality. The BFI provides a score for the five major traits that define human personality across cultures: Neuroticism, Extraversion, Openness, Agreeableness and Conscientiousness. These constructs are complemented with a set of questions aimed to measure the respondents' external Locus of Control, i.e., the extent to which respondents feel they are not in command of their circumstances, and a measure on individual's positive and negative reciprocity, an important concept in social psychology capturing how individuals respond to other individuals' actions. In our analysis, the dependent variable is a subjective measure of life satisfaction, which can be regarded as a proxy for individual utility.

To date estimates of the effect that income comparisons exert on life satisfaction have been calculated in an "average" sense, with the exception of two new working papers examining 
the life-cycle patterns of income comparisons (FitzRoy et al., 2011 and Akay and Martinsson, 2012). This is the first paper to relax the assumption that individuals respond identically to societal information regardless of their personality. A corpus of field and laboratory experiments in psychology has proven the importance of the interplay between personality traits and the responsiveness to social comparisons. The response to hedonically relevant information, including social comparisons, is typically found to depend on specific personality traits such as self-esteem, optimism, neuroticism and extraversion (Wheeler and Miyake, 1992, Aspinwall and Taylor, 1993). The extent and consequences of social comparisons is also found to differ between those individuals with a predisposition to be happy or unhappy. In general, individuals with a predisposition to be happy think more positively about themselves, feel more personal control, react more intensely to positive events and life outcomes, and show shorter drops in affect in response to unfavorable life events (Seidlitz et al., 1997, Lyubomirsky and Tucker, 1998). Comparison information appears to hurt unhappy individuals when it is unfavorable, but does not help them when it is favorable. Happy individuals instead do not appear to be hurt by unfavorable social information (Lyubomirsky and Ross, 1997, and Lyubomirsky et al., 2001).

In contrast with this above mentioned literature based on small scale psychological experiments, this paper relies on economic data and a large scale survey to document existing differences between personality groups regarding the relationship between comparison income and life satisfaction. Although the role of personality in shaping individual sensitiveness to income comparisons has never been examined using subjective satisfaction questions, the happiness literature does argue that the most important component of individual heterogeneity in SWB equations is an individual's personality (Boyce, 2010). Consistent with this view, researchers in the field have acknowledged the importance of controlling for individual heterogeneity when estimating life satisfaction equations (Ferrer-iCarbonell and Frijters, 2004). In economics, the use of explicit personality measures is very much in its infancy, however, and we still have a poor idea of how and to what extent the effect of socioeconomic factors on an individual's life satisfaction is driven by his/her personality. The causal effect of income on life satisfaction is particularly relevant, due to important policy consequences. Recent research points to significant differences in the elasticity between income and life satisfaction among different personality groups (Boyce and 
Wood, 2011, Proto and Rustichini, 2011) and in the speed of adaptation to certain life events such as unemployment (Boyce et al., 2010b). By focusing on income comparisons, this paper addresses another aspect of an individual's financial situation and how it impacts individuals' utility.

In fact, the use of personality measures in economics is becoming stronger. There is growing evidence on the relationships between personality and a variety of life outcomes, including health, criminal activity and economic success (for a survey, Almlund et al., 2011). Complementary work provides evidence that non-cognitive skills affect a wide range of labor market outcomes such as occupational choices (Ham et al., 2009), job search effort (Caliendo et al., 2010), employment (Mohanty, 2010, Uysal and Pohlmeier, 2011) and, especially, earnings (Groves, 2005, Nyhus and Pons, 2005, Mueller and Plug, 2006, Semykina and Linz, 2007, and Heineck and Anger, 2010), These conspicuous effects have led researchers to argue that personality should be given greater consideration in economics (Borghans et al., 2008). This paper forms part of the emerging interest on personality data, which in economics has disregarded social comparison processes to date.

The results in section 5 point to a heterogeneity of the importance of income comparisons. In other words, the effect on life satisfaction of the rank (position) that individuals occupy within their reference group varies largely across personality groups. People are more sensitive to income comparisons when ranking high on neuroticism and extraversion, when on the top and the bottom of agreeableness, and when ranking low on negative reciprocity and external locus of control. There is a group of individuals who instead are very insensitive to income comparisons, notably those at the bottom of the distribution of neuroticism, extraversion and positive reciprocity; and those at the top and average of the distribution of negative reciprocity. These differences across individuals should be taken into account when for example, introducing these types of externalities into economic models, in predicting individuals' behavior, or in making welfare judgments.

The paper is organized as follows: Section 2 introduces the previous literature; section 3 discusses the data and the measures used in this paper; section 4 presents the empirical 
approach; section 5 shows and discusses the results; and section 6 presents the concluding remarks.

\section{Previous literature}

Income externalities, including consumption externalities, have important implications for a variety of policy relevant issues at the micro and the macro level, including optimal taxation, public redistribution and the welfare costs of aggregate fluctuations (Frey and Stutzer, 2002; Di Tella and MacCulloch, 2003; Senik, 2005; and Clark et al., 2008a). In addition, they are a part of human behavior and therefore their understanding contributes to better predict individuals' reaction to policy changes or their behavior in the various markets.

The income rank hypothesis states that people gain utility from occupying a higher ranked position. The empirical evidence using self-reported satisfaction data suggests that individuals are indeed rank sensitive. Clark et al. (2009) match individual economic satisfaction scores from eight years (panel data) of the Danish European Community Household Panel (ECHP) with administrative data to calculate individuals own income and the income distribution of their neighborhood. They find evidence that individual reported financial satisfaction depends significantly and positively on the income rank that the households occupy in the neighborhood. Specifically, a 1-decile increase in the family rank is as important ceteris paribus as a 1.6 units increase in log income or, to put it different, to a raise in absolute income by a factor of almost 5 . Based on Indonesian cross-section data from the year 2000 , Powdthavee (2009) provides very similar estimates when using respondents' perception on own relative economic position as dependent variable. Brown et al. (2008) use the 1998 cross-section data from the UK to document how the worker's rank within the workplace earnings distribution affects self-reported levels of satisfaction in different job domains. Their results also suggest that the rank has a positive effect on job domains satisfaction.

Previously to the above mentioned results, researchers using satisfaction data as a proxy to measure utility based their reference group studies on examining the effect of the mean income level of the reference group rather than looking at the rank that respondents occupied. Those studies found a negative effect of the reference group mean income on self-reported 
satisfaction (Blanchflower and Oswald, 2004; Ferrer-i-Carbonell, 2005; Luttmer, 2005; Senik, 2009). The robustness of this effect is remarkable except for the positive coefficient found by Senik (2004) in Russia during the 1994-2000 transition period. Senik suggests however that when living under such levels of economic uncertainty the comparison status effect (whereby comparison income makes people feel relatively deprived) can be more than offset by the positive effect that it has as a signal about own future prospects. A similar result is reported in Caporale et al. (2009) for Eastern European countries and in Clark et al. (2009b) for job (not life) satisfaction data when using co-workers as the comparisons group. In this later case, higher wages of work colleagues have a positive effect on job satisfaction because they are seen as a signal of good expectations about own wages in the future.

The only work relating income rank to self-reported life satisfaction data is Boyce et al. (2010). They use pooled data from the BHPS to test for relative income effects using both, the average income of the reference group and the income rank model and find evidence in favor of the later.

\subsection{A practical question: the definition of reference groups}

A still rather open question in the literature is the identification of the relevant group, as there is very scarce evidence on who people take as reference group. In the empirical literature one can find several approaches. Some authors rely on a pure geographical approach by assuming that comparisons take place among people living in the same geographical area. The level of aggregation varies greatly across studies, ranging from countries (Di Tella and MacCulloch, 2003), American states (Blanchflower and Oswald, 2004), Public Use Microdata Areas in the US (Luttmer, 2005) and census tract in Canada (Helliwell and Huang, 2010) to neighborhoods (Clark et al., 2009a; Dittmann and Goebel, 2010) and Indonesian sub-districts (Powdthavee, 2009). Other authors consider that comparisons take place only between those in the same cohort (McBride, 2001), with similar characteristics (Senik, 2004; Ferrer-iCarbonell, 2005), or in the same workplace when it comes to satisfaction in the job (Brown at al., 2008; Clark et al., 2009b). The reference level corresponds, thus, to the 'typical' income of individuals of given characteristics. 
A related body of research has directed efforts towards understanding the endogenous determination of reference groups by directly asking individuals about the direction of their comparisons (Falk and Knell, 2004; Senik, 2009; Clark and Senik, 2010). The evidence points to some degree of heterogeneity in the choice of the relevant groups. In an endogenous context, however, assessing the impact on life satisfaction of the benchmark income would require gathering data on the groups pointed out by the individual, which renders the analysis unfeasible outside a laboratory. A related concern is that, due to data limitations, it remains to be tested whether the self-reported importance of the different groups is a good predictor of their actual importance in a life satisfaction or happiness equation.

\section{Data and measures of personality}

\subsection{Data}

Conducted in Germany since 1984, the German SOEP is a wide-ranging representative longitudinal study of households that contains a large set of personal, family and labor market characteristics of household members (for details see Wagner, Frick and Schupp, 2007; and Frick, et al., 2007). In 2005 the panel includes a set of questions aimed at capturing various concepts of personality: the BFI, Locus of Control (LOC) and negative and positive reciprocity. Since these questions were only asked in 2005 and despite the fact that personality traits tend to be quite time consistent and that we corrected for observable determinants of all these measures of personality (see section 3.2.1), the empirical analysis will focus on the years around 2005 only. In concrete we use years 2000 to 2008. After dropping observations with missing values in the relevant variables we retain 140,572 observations.

In the SOEP, the life satisfaction question runs as follows:

- How satisfied are you with your life, all things considered?

The answer to this question takes discrete values from 0 to 10 and hereafter will be referred to as Life Satisfaction (LS). Despite a long tradition among sociologist and psychologist, subjective data was subject to criticisms among some economists concerned about the potential biases arising from cultural differences, framing problems, cognitive bias and mood 
effects. For reasons of space, the present paper overlooks such discussion by simply noting that the evidence accumulated over recent years has persuaded most readers and researchers about the validity and consistency of self-reported data. In a nutshell, subjective measures of satisfaction and well-being have a predictive power over relevant actions and are related (in the expected direction) to a number of objective indicators including physical health and longevity (Danner et al., 2001), suicide rates and macroeconomic fluctuations (Di Tella et al., 2003), unemployment (Clark et al., 2008b) and to measures of revealed preferences (Clark and $\mathrm{Wu}, 2010)$. These measures also show a reasonable amount of internal consistency and temporal reliability: they correlate well with one another and with alternative methods of measurement, including ratings made by family and friends, facial measures of emotion and a vast array of psychological and psychosocial indicators (Cacioppo et al., 2008).

Table 1 contains the summary statistics of the sample. The average LS over the sample period is 6.96 (s.d. = 1.75). Satisfaction answers are skewed; individuals tend to be fairly happy with their lives, with almost $46 \%$ of the sample reporting a LS score above 7 and only $2 \%$ reporting below 3. Average family income amounts to 2,932 euros. The average educational attainment is 12.1 years of schooling and the average age is 48.4 years. Women account for $52.1 \%$ of the sample. Most individuals are married or live with a partner (66.3\%) and are employed (62.9\%). In the regression stage, the continuous variables family income, age and age squared, years of completed education, number of children and adults at home are entered in their logarithm form so as to take into account their decreasing marginal contribution to life satisfaction. The logarithmic relationship between income and life satisfaction is well documented. In order to consider heterogeneous household size and cost-of-life adjustments, all income-based variables in the paper are transformed using the OECD equivalence scale ${ }^{\mathrm{i}}$ and normalized into real terms using the yearly consumer price index.

\subsection{Non-cognitive skills}

Individuals in the questionnaire are asked to respond to a series of items included in the BFI and other related to LOC and negative and positive reciprocity. The Big Five and the LOC

\footnotetext{
${ }^{\mathrm{i}}$ The OECD equivalized household size, $\mathrm{E}$ is defined as follows: let $\mathrm{A}$ be the number of household members who are older than 14 , and let $\mathrm{S}$ be the household size, then $\mathrm{E}=1+0.7 \times(\mathrm{A}-1)+0.5(\mathrm{~S}-\mathrm{A})$.
} 
measures are two alternative well known ways to evaluate different characteristics of individuals' personality. LOC aims at capturing the degree to which individuals believe that they can control the events that affect their life. The BFI is directed at measuring the different dimensions of humans' personality. The positive and negative reciprocity items relate to an important concept in social psychology aimed at measuring individuals negative and positive responses to other individuals' actions.

The BFI represents a widely accepted approach to conceptualizing personality (Costa and McCrae, 1992). After aggregating across items, the BFI provides a single score for each of the five major traits that define human personality across cultures: Neuroticism, the tendency to experience negative emotions such as anxiety and depression; Extraversion, the tendency to be sociable, warm, active, assertive, cheerful, and in search of stimulation; Openness to experience, the tendency to be imaginative, creative, unconventional, emotionally and artistically sensitive; Agreeableness, the dimension of interpersonal relations, characterized by altruism, trust, modesty, and cooperativeness; and Conscientiousness, a tendency to be organized, strong-willed, persistent, reliable, and a follower of rules and ethical principles. The BFI questionnaire used in the German SOEP is based on 3 items for each personality dimension, which makes a total of 15 items. Despite psychologists typically work with longer questionnaires, the shortened version introduced in the German SOEP and used in this paper, known as the BFI-S, has been validated against longer inventories (Dehne and Schupp, 2007; Lang et al., 2011). The 15 BFI-S items are:

I see myself as someone who: (i) worries a lot, (ii) gets nervous easily, (iii) is relaxed, handles stress well, (iv) is communicative, talkative, (v) is outgoing, sociable, (vi) is reserved, (vii) is original, comes up with new ideas, (viii) values artistic experiences, (ix) has an active imagination, (x) is sometimes somewhat rude to others, (xi) has a forgiving nature, (xii) is considerate and kind to others, (xiii) does a thorough job, (xiv) does things effectively and efficiently, and (xv) tends to be lazy.

The first three items relate to neuroticism; the second set to extraversion, openness to experience, agreeableness, and the last 3 items to conscientiousness. For most items, the respondent casts their answers on a 1 to 7 scale, where 1 stands for "does not apply to me at 
all" and 7 for "applies to me perfectly". Some items however are reversely scored, i.e., a higher score negatively correlates with the dimension under evaluation. The measure used in the regression analysis for each of the 5 personality traits is an average across items and therefore can range from 1 to 7 . An important issue in personality measures is the concern that variability in the resulting scores arise from measurement error. In our data, encompassing tests of internal consistency were satisfactory ${ }^{\mathrm{ii}}$.

LOC is a measure of the degree to which individuals feel the control of their life is on their own hands (internal) or depends of external factors (external). People with a high score in the items measuring external LOC believe that fate, luck, or any other external circumstances determine the course of their lives; while those with a high score on internal LOC perceive that their life depend on own behavior and efforts. The notion of LOC was developed by Julian Rotter and since then it has become an important concept to define personality within psychology. Lockwood (2002) found that the extent to which one finds social comparisons inspiring or threatening depends on whether one finds a sense of control over the dimension under evaluation. In the SOEP, LOC is surveyed with 10 items: the first four relate to internal LOC and the other six are aimed to measure external LOC. These are:

(i) My life course depends on me, (ii) influence on social conditions through involvement, (iii) success takes hard work, (iv) doubt my abilities when problems arise, (v) haven't achieved what I deserve, (vi) what you achieve depends on luck, (vii) others make the crucial decisions in my life, (viii) possibilities are defined by social conditions, (ix) abilities are more important than effort, (x) little control over my life.

Unfortunately, internal LOC was found to exhibit a very limited amount of construct validity in the data ${ }^{\mathrm{iii}}$, meaning that the surveyed items are not at all appropriate for measuring the

\footnotetext{
ii A principal component analysis with varimax rotation was conducted. Factor analyses clearly replicated the Big Five factors by yielding a correlation matrix with five eigenvalues above unity. The five principal components accounted for $60.7 \%$ of the total variance. The Cronbach's alphas for the five dimensions were $0.607,0.657,0.625,0.505$ and 0.609 , respectively. It must be noticed that for a given level of internal consistency, fewer items per dimension result into lower alphas (Mueller and Plug, 2006). Hence, although these reliability coefficients are towards the lower range of admissible values, they point to a reasonable amount of internal consistency given the low (3) number of items per personality traits.

iii The alpha reliability coefficient was as low as 0.201 .
} 
underlying scale. This forced us to exclude internal LOC from the analyses and focus exclusively on external LOC, i.e. the last six items. The respondents have to answer each item on a 1 to 7 scale, where 1 stands for "disagree completely" and 7 for "agree completely". The measure used in the regression is an average over the six items. A high score indicates that the individual feels that her or his life is much driven by external factors such as luck.

Our last measure of non-cognitive skills is reciprocity, which is computed by six items of which three refer to cooperative tendencies ("positive reciprocity") and the other three to retaliatory aspects ("negative reciprocity"). The positive reciprocity items are:

(i) if someone does me a favor, I am prepared to return it, (ii) I go out of my way to help somebody who has been kind to me before, (ii) I am ready to undergo personal costs to help somebody who helped me before.

The negative reciprocity items are:

(i) if I suffer a serious wrong, I will take revenge as soon as possible, no matter what the cost, (ii) if somebody puts me in a difficult position, I will do the same to him/her, and (iii) if somebody offends me, I will offend him/her back.

As in the other measures, the respondent can cast their response for each of these two items on a 1 to 7 scale, and the proxy used in the regression analysis is the average of the two scores. Despite the reduced number of items, the internal consistency of these two constructs is remarkably large $\mathrm{e}^{\mathrm{iv}}$.

Table 2 shows the sample averages for each of the personality measures ( 8 in total). In the regressions stage of the paper, all the personality measures were normalized to a mean zero and unit variance to ease the interpretation of the results. Figure 1 shows the density function of the normalized scores. The graphs show that only a few of the traits are not normally

\footnotetext{
iv The Cronbach's alphas for the two dimensions were 0.622 and 0.822 , respectively. Auxiliary factor analysis supported the existence of two orthogonal factors, thus validating the a priori distinction between positive and negative reciprocity.
} 
distributed namely, conscientiousness, agreeableness and positive reciprocity, all of which are left-skewed.

\subsubsection{The stability of non-cognitive skills}

The three different measures of personality (BFI, LOC and reciprocity) were gathered only in the 2005 wave of the German SOEP. To deal with this limitation, we relax the often imposed assumption that these constructs are constant over the period of analysis. We do that even though the time persistence of personality should not be seen as a stringent assumption, as it is generally accepted that adult's personality traits are fairly stable over time (Roberts and Del Vecchio, 2000, Costa and McCrae, 2002). In our sample, the respondents mean age is 48 years and on average they are interviewed during no more than 7 consecutive years, so that the potential interdependency between early life events and personality should not play much of a role. Still, some concerns may persist under the light of recent studies pointing to changes in personality traits over the life cycle and following changes in one's social and job environment. Aging is the most prominent factor put forward in those studies, with people steadily becoming more agreeable, conscientious and less neurotic over the life cycle (Roberts et al., 2006, Soto et al., 2011). Environmental factors and major life events, including marriage, divorce, widowhood, and transitions into an out of employment, may also affect personality (Kandler et al. 2010, Specht et al., 2011).

To address these concerns, in this paper we regress each personality trait on age and age squared, labor market status (employed, unemployed, reference: inactive) and marital condition (single, divorce, widowed, reference: married). The predicted residuals are free from this specific life events and, therefore, used as the relevant measures of personality. Expanding the set of regressors to include additional variables such as income, health and region or, alternatively, using the raw measures of personality lead to very similar results. In addition to using the predicted residuals, and given that personality measures were asked in 2005 , the empirical analysis only uses the years 2000-2008 of the panel data. 


\section{Method of analysis}

\subsection{Estimating procedure}

Life Satisfaction (LS) is assumed to be a function of personal and demographic characteristics,

$$
L S=f\left(L S^{*}(X, y, r)\right)
$$

where $X$ is a vector of socio-economic characteristics, $y$ is family income and $r$ is the household normalized rank in terms of income within the reference group. The rank is defined as the position of individual $i$ in terms of his or her family income as a proportion of the number of families in group $g$. This is: $\left(\mathrm{P}_{\mathrm{ig}}-1\right) /\left(\mathrm{N}_{\mathrm{g}}-1\right)$, where $\mathrm{P}_{\mathrm{ig}}$ is the position of individual $i$ in group $g$, and $\mathrm{N}_{\mathrm{g}}$ is the number of individuals in the group. Normalized rank is zero for the poorest household in the group and one for the richest household.

We take reported LS to be cardinal. This is, we assume that the distance between the eleven satisfaction categories carry a meaning. It has been shown that assuming cardinality as oppose to regress satisfaction with ordinal models is rather irrelevant for the results in terms of trade-offs between explanatory variables (Ferrer-i-Carbonell and Frijters, 2004) while it has the advantage of yielding coefficients that can be directly interpreted as marginal effects. We rely on the Probit Adapted Ordinary Least Squares (POLS) as developed by Van Praag and Ferrer-i-Carbonell (2008, p. 29-34). Implementing POLS begins by deriving $\left\{\mu_{j}\right\}_{j=0}^{J}$ values of a standard normal associated with the cumulative frequencies of the $J$ different categories of the dependent variable, with $\mu_{0}=-\infty, \mu_{J}=\infty$ Then the expectation of a standard normally distributed variable is taken for an interval between any two adjacent values. Thus if the true unobserved continuous variable for individual $i$ at time $t$ is $S W B_{i t}^{*}$ where the observed is $L \mathrm{~S}_{i t}=j$ if $\mu_{j-1}<L \mathrm{~S}_{i t}^{*}<\mu_{j}$ for $j=1, \ldots, J$, then the conditional expectation of the latent variable is given by:

$$
L \ddot{S}_{i t}=E\left(L S_{i t}^{*} \mid \mu_{j-1}<L S_{i t}^{*}<\mu_{j}\right)=\frac{n\left(\mu_{j-1}\right)-n\left(\mu_{j}\right)}{N\left(\mu_{j}\right)-N\left(\mu_{j-1}\right)}
$$


where $n$ is the normal density and $N$ is the cumulative normal distribution. This approach allows the inclusion of individual fixed effects and the application of a linear estimator on the conditional expectations, which is assumed to be a function of observable characteristics

$$
L \ddot{S}_{i t}=\alpha X_{i t}+\beta y_{i t}+\gamma r_{i t}+v_{i}+\varepsilon_{i t}
$$

where $X$ includes age and age squared, years of completed education, household size (number of children and number of adults at home) and additional dummy variables for gender, marital condition, employment status, immigrant condition and health status. Year fixed effects and controls for the 16 German federal states are included as additional explanatory variables. The term $v_{i}$ represents the individual fixed effect and $\varepsilon_{i t}$ an iid error term.

Since we assume that personality is constant over time (see section 3.2.1), a fixed effect model does not allow for an exploration of the personality-dependent effects by simply including the personality measures and interaction terms in the estimation of equation (3). Instead, we define for each personality trait three groups of individuals depending on whether they are in the top $25 \%$ of the distribution of the corresponding personality score, in the bottom $25 \%$, or comprised in the $75 \%-25 \%$ interval. In the empirical analysis, we will run separate equations for each of these groups and personality.

\subsection{Definition of reference group}

This paper follows a mixed approach in which several demographic dimensions are simultaneously considered. In the empirical operationalization of the reference group, we partition the sample into various groups using the geographical region where the household lives (West or East Germany), gender of the respondent, education attainment of the respondent (less than 10,10,11, 12 and more than 12 years of schooling), and age of the respondent (younger than 25, 25-34, 35-44 and older than 65). The combination of these criteria produces 100 different groups $^{\mathrm{v}}$. In this approach individuals are assumed to compare themselves with (and thus to have information on) the income level of a household like

\footnotetext{
${ }^{\mathrm{v}}$ The average number of individuals in a group ranges from a minimum of 10 to a maximum of 4,484 at an average of 1650.7 (s.d. $=1725.9$ ).
} 
them ${ }^{\mathrm{vi}}$. Then, the rank that an individual occupies is given by the household relative position within that specific cell.

Note that the reference group is defined at the individual rather than at the household level, while the individual income is operationalized as family income. Individuals are regarded to have their own reference group, which is not always the same as the one of their partner, while they are assumed to pool income within the household (this is, the income they enjoy is equal to the family income).

\section{Results: the effect of rank and the role of the non-cognitive skills}

Table 3 reports the estimates corresponding to the total sample and to the different personality subsamples. The results are supportive of the prominent role of personality as a mediating force on the importance of relative income for life satisfaction. In other words, the results show a clear heterogeneity on the effect that comparison income has on happiness or life satisfaction. While some individuals tend to be rank insensitive (e.g., non-extraverts) others are much affected by their position on the income distribution (e.g., most extraverts individuals). Using the results in Table 3 we test, for each personality trait, whether the differences of the rank coefficient between the different segments of the distribution are statistically significant. According to the t-tests (Table 4), the equality of the coefficients between individuals at different points of the distribution of the personality trait is strongly rejected.

The partition of the sample according to personality also yields statistically significant differences of the income coefficient, i.e., personality plays a role on the importance that income has on LS or, in other words, the marginal utility of income differs across personalities. Such differences are however smaller than the ones we find for the importance of income comparisons (the rank coefficient). Boyce and Wood (2011) also found differences on the marginal utility of income depending on the individual personality, although our results are not identical to theirs. The dissimilarities may be driven by two main differences

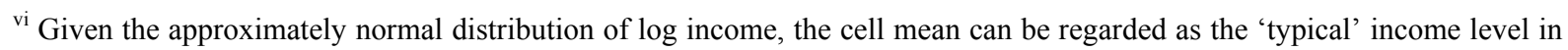
the group.
} 
between the two papers: (i) we use a larger set of personality measures, and (ii) Boyce and Wood (2011) do not run separate regressions for each subsample but run the model with interactions arguing that the personality effect is already included in the model through the individual fixed effect.

On average (i.e., aggregating all individuals) the rank effect amounts to 0.070 (first column of Table 3 ) and it is significant at the $1 \%$ level. In terms of the trade-off between rank and own income, individuals would need a compensation of about $66 \%$ of their current income to move from the top $(r a n k=1)$ to the bottom $(r a n k=0)$ of the income distribution of their reference group (i.e., $\exp (0.070 / 0.138)-1) \times 100=66.1 \%)$. The rank income effect can become much larger when we separate individuals according to their personality. For example, for someone with low external LOC (someone who does not think that external circumstances have a major role in their life) the needed compensation is not 66 but $212 \%$. While on average a 1-decile increase in rank is as important in terms of life satisfaction as a $5.2 \%$ increase in household income, this amount more than triplicates among individuals with low external LOC (16.9\%), negative reciprocity (18.3\%) and high extraversion (18.6\%). This compensation is also above-average among people with high neuroticism (14.4\%) and either high $(8.6 \%)$ or low $(8.2 \%)$ agreeableness. In contrast, rank appears to be largely insignificant in explaining LS among a number of groups, notably those at the bottom of the distribution of neuroticism, extraversion, and positive reciprocity; and those at the top and average of the distribution of negative reciprocity.

In short, and if we take into account the statistical significance and difference of the coefficients, the results using individual fixed effects and assuming cardinality clearly show that rank is particularly relevant for the LS of those individuals ranking high on neuroticism, extraversion, for those on the top and the bottom of agreeableness and for those ranking low on negative reciprocity and external LOC.

An important question that arises is whether these findings, based on economic data and a large scale survey, are in line with laboratory research in the field of psychology. We find common ground for conscientiousness, neuroticism and LOC. There are results in the literature showing that conscientious individuals tend to value wealth accumulation (Ameriks 
et al., 2003), set themselves higher goals and care more about achieving them (Barrick et al., 1993; DeNeve and Cooper, 1998). It is likely that such a predisposition enlarges the importance of income comparisons. This may partially explain the results in our data, where individuals at the bottom of the conscientiousness distribution are rather rank insensitive. As for neuroticism, it is linked to higher sensitivity to negative emotions like anger, hostility or depression (Clark and Watson, 2008), and modern studies identify this personality trait with sensibility to negative outcomes, threats and punishments (see DeYoung and Gray, 2010, for a recent survey). Neurotic people respond more sensitively to social comparisons, regardless whether they are downwards or upwards (Van der Zee et al., 1998), and individuals with low self-esteem, a related aspect of neuroticism, are more sensitive to comparisons both improving more their mood after comparing with worse-off others and responding more negatively after comparing with better-off others (Wheeler and Miyake, 1992; Aspinwall and Taylor, 1993). The results in this paper suggest that to a large extent these views can be expanded to the realm of income comparisons. Finally, the extent to which one finds social comparisons inspiring or threatening is known in the field of psychology to depend on whether one finds a sense of control over the dimension under evaluation. The results, based on economic data, support this intuition. People with low external LOC believe that her behavior is guided by her personal decisions and efforts and not by external circumstances and reap lower emotional benefits from an advantageous position (Wood and Van der Zee, 1997). Interestingly, we find that this group is particularly sensitive to rank variations, probably because they are more prone to blame and credit themselves for their economic status.

The available evidence for reciprocity is very scarce. Fehr and Gächter (2000) argue that positive reciprocity has powerful implications for many economic domains, including the enforcement of explicit social norms. Norm-governed attitudes, social interactions and conformism among peers, relatives and in neighborhoods may have important consequences for use and perception of individual and public resources. The higher rank sensitiveness among the positive reciprocal comes as no surprise if we take into account that being positively reciprocal predicts higher work effort (Dohmen et al., 2009), a result that is expected to increase the psychological cost of the gap between aspirations and realized income. Moreover, they are presumably more aware of their social relations, as positive reciprocal individuals 
have a greater a number of close friends. It is thus not surprising that individuals at the bottom of the positive reciprocity are rank insensitive as compared to the other individuals in the distribution.

\section{Conclusions}

This paper uses economic data from a large scale survey to document existing differences between personality groups (or more broadly non-cognitive skills) concerning income comparisons. Previous research in psychology, confined to laboratory studies, pointed to important personality effects in the response to social comparisons. The results of this paper, based on fixed effects estimates from the 2000-2008 waves of the German Socio-economic Panel and three different sets of non-cognitive skills indicators, are suggestive of substantial differences across groups. We have found consistent evidence that the importance of income rank for individuals' reported life satisfaction varies significantly across individuals endowed with different sets of non-cognitive skills.

A first implication of our findings regards the design of economic models. In word of Clark et al. (2008a) "taking relative income seriously is an important step toward greater behavioral realism in Economics, such that our models and empirical analysis move closer to how real people feel and behave". At the theoretical level, the distinction between absolute and relative formulations of utility has proven a useful concept to rationalize a large set of unexplained phenomena in a variety of fields, including consumption, savings, growth and financial regularities. Acknowledging the extent of individual heterogeneity surrounding relative effects would prove fruitful to bring closer the theory to data and, most probably, to account for yet unexplained phenomena.

As a second implication, welfare analysis should take into account the diverging importance of income externalities, for example, when designing optimal income taxation or defining poverty. The poverty literature has explicitly argued that relative concerns matter for individuals and some researchers have consequently defended that we should base the poverty line on relative rather than absolute consumption. Although in practice taking personality differences into account for relative poverty measures would be very difficult, our 
results warn that imposing a common benchmark might be seriously misleading. This concern also applies to the welfare analysis of deprivation and social exclusion promoted within the Europe 2020 Strategy.

Finally, and to the extent that individuals behave so as to improve their life satisfaction (Heffetz et al., 2012), the importance of relative income will partly drive individuals' behavior in several life domains. Therefore, understanding the heterogeneity of preferences over relative income will help us to understand individuals' behavior in the markets. For example, status motives are an important determinant of labor supply and of amount of effort at work (Neumark and Postlewaite, 1998). Our results suggest that individuals endowed with different set of non-cognitive skills may respond very differently to relative income concerns. A next natural step would be to test these hypotheses using labor market data. 


\section{References}

Abel, A. (2008). Equity Premia with Benchmark Levels of Consumption: Closed-Form Results. In Rajnish Mehra (ed.), Handbook of the Equity Risk Premium, Amsterdam: Elsevier, 117 - 157.

Akay, A. \& P. Martinsson (2012). Positional Concerns through the Life Cycle: Evidence from Subjective Well-Being Data and Survey Experiments. IZA Discussion Paper 6342.

Almlund, M., A.L. Duckworth, J.J. Heckman \& T.D. Kautz, (2011). Personality Psychology and Economics. NBER Working Papers, 16822, National Bureau of Economic Research, Inc.

Ameriks, J., A. Caplin, \& J. Leahy (2003). Wealth accumulation and the propensity to plan. Quarterly Journal of Economics, 118, 1007-1047.

Aspinwall, L. G. \& S.E. Taylor (1993). Effects of social comparison direction, threat, and self-esteem on affect, self-evaluation, and expected success, Journal of Personality and Social Psychology, 64, 708-722.

Barrick, M., M. Mount, M. \& J. Strauss (1993). Conscientiousness and performance of sales representatives - test of the mediating effects of goal setting. Journal of Applied Psychology, 78, 715-722.

Blanchflower \& A. Oswald (2004). Well-being over time in Britain and the USA. Journal of Public Economics, 88, 1359-1386.

Borghans,L., A. Duckworth, J. Heckman \& B. ter Weel (2008). The economics and psychology of personality traits, Journal of Human Resources 43(4), 972-1059.

Boyce, C. J. (2010). Understanding fixed effects in human well-being, Journal of Economic Psychology, 31, 1-16

Boyce, C., G. Brown \& S. Moore (2010a). Money and happiness: rank of income, not income, affects life satisfaction. Psychological Science, 21(4), 471-475.

Boyce, C., A.M. Wood \& G. Brown (2010b). The dark side of conscientiousness: Conscientious people experience greater drops in life satisfaction following unemployment. Journal of Research in Personality, 44, 535-539.

Boyce, C. J., \& A.M. Wood (2011). Personality and the marginal utility of income: Personality interacts with increases in household income to determine life satisfaction. Journal of Economic Behavior \& Organization, 78, 183-191.

Brown, G., J. Gardner \& A. Oswald (2008). Does Wage Rank Affect Employees' Well-being?, Industrial Relations, 47(3), 355-389.

Cacioppo, J., L.C. Hawkley, A. Kalil, M.E. Hughes, L. Waite \& R.A. Thisted (2008). Happiness and the Invisible Threads of Social Connection: The Chicago Health, Aging and Social Relations Study. In The Science of Subjective Well-Being, M. Eid and R.J. Larsen (Eds.), The Guilford Press, New York. 
Caliendo, M., D. Cobb-Clark \& A. Uhlendorff (2010). Locus of Control and Job Search Strategies. IZA Discussion Paper No. 4750.

Campbell, J. \& J. Cochrane (1999). By force of habit: A consumption-based explanation of aggregate shock market behavior, Journal of Political Economy, 107(2), 205-251.

Caporale, G.M., Y. Georgellis \& Y.P. Yin (2009). Income and happiness across Europe: Do reference values matter? Journal of Economic Psychology, 30, 42-5.

Carroll, C., J. Overland, \& D. Weil (2000). Saving and growth with habit formation. American Economic Review, 90(3), 341-355.

Clark, L.A., \& Watson, D. (2008). Temperament: An organizing paradigm for trait psychology. In O.P. John, R.W. Robins, and L.A. Pervin (Eds.), Handbook of personality: Theory and research, 265-286). New York: Guilford Press.

Clark, A.E., P. Frijters \& M. Shields (2008a). Relative income, happiness and utility: an explanation for the Easterlin paradox and other puzzles. Journal of Economic Literature, 46, 95-144.

Clark, A.E., E. Diener, Y. Georgellis \& R.E. Lucas (2008b). Lags And Leads in Life Satisfaction: a Test of the Baseline Hypothesis. Economic Journal, 118(529), 222-243.

Clark, A., N. Kristensen \& N. Westergaard-Nielsen (2009a). Economic Satisfaction and Income Rank in Small Neighbourhoods. Journal of the European Economic Association, 7(2-3), 519-527.

Clark, A., N. Kristensen \& N. Westergaard-Nielsen (2009b). Job Satisfaction and Co-Worker Wages: Status or Signal? Economic Journal, 119(536), 430-447.

Clark, A. \& S. Wu (2010). Objective Confirmation of Subjective Measures of Human Well-being: Evidence from the USA. Science 327(5965), 576-579.

Clark, A. \& C. Senik (2010). Who Compares to Whom? The Anatomy of Income Comparisons in Europe. Economic Journal, 120(544), 573-594.

Costa, P.T., \& R.R McCrae (1992). NEO PI-R. Professional manual. Odessa, FL: Psychological Assessment Resources, Inc.

Costa, P. T. \& R.R McCrae (2002). Looking backward: Changes in the mean levels of personality traits from 80 to 12. In D. Cervone and W. Mischel (Eds.), Advances in personality science, New York: Guilford Press, 219-237.

Danner, D., D.A. Snowdon \& W.V. Friesen (2001). Positive emotions in early life and longevity: findings from the nun study, Journal of Personality and Social Psychology, 80, 804-813.

Dehne, M. \& J. Schupp (2007). Personlichkeitsmerkmale im Sozio-oekonomischen Panel (SOEP): Konzept, Umsetzung und empirische Eigenschaften. DIW Berlin, Research Note 26.

DeNeve, K. \& H. Cooper, H. (1998). The happy personality: A meta-analysis of 137 personality traits and subjective well-being. Psychological Bulletin, 124, 197- 229. 
DeYoung, C., J.B. Hirsh, M.S. Shane, X. Papademetris, N. Rajeevan, \& J. Gray (2010). Testing predictions from personality neuroscience: Brain structure and the Big Five. Psychological Science, $21,820-828$.

Díaz, A., J. Pijoan-Mas \& J.V Ríos-Rull (2003). Precautionary savings and wealth distribution under habit formation preferences. Journal of Monetary Economics, 50(6), 1257-1291.

Diener, E. \& R. Lucas (1999). Personality and subjective well-being, in Well-being: the foundations of hedonic psychology, In D. Kahneman, E. Diener \& N. Schwarz (eds.). New York: Sage.

Di Tella, R., R. MacCulloch, \& A. Oswald (2003). The macroeconomics of happiness, Review of Economics and Statistics, 85(4): 809-827.

Dittmann, J. \& J. Goebel, (2010). Your House, Your Car, Your Education: The Socioeconomic Situation of the Neighborhood and its Impact on Life Satisfaction in Germany. Social Indicators Research, 96, 497-513.

Dohmen, T., A.Falk, D. Huffman \& U. Sunde (2009). Homo Reciprocans: Survey Evidence on Behavioural Outcomes. Economic Journal, vol. 119(536), 592-612.

Falk, A. \& M. Knell (2004). Choosing the Joneses: Endogenous Goals and Reference Standards. Scandinavian Journal of Economics, Blackwell Publishing, 106(3), 417-435.

Fehr, E. \& S. Gächter (2000). Fairness and retaliation. Journal of Economic Perspectives, 14(3), 15981.

Ferrer-i-Carbonell, A. \& P. Frijters (2004). How important is methodology for the estimates of the determinants of happiness? The Economic Journal, 114, 641-659.

Ferrer-i-Carbonell, A. (2005). Income and Well-being: An Empirical Analysis of the Comparison. Income Effect. Journal of Public Economics, 89, 997-1019.

FitzRoy, F., M. Nolan, \& M.F. Steinhardt (2011). Age, life-satisfaction, and relative income, HWWI Research Paper, 110.

Frick, J.R., S.P. Jenkins, D. R. Lillard, O. Lipps \& M. Wooden (2007). The cross-national equivalent file (CNEF) and its member country household panel studies. Schmollers Jahrbuch, 127, 627-654.

Frey, B. \& A. Stutzer (2002). What can economists learn from happiness research? Journal of Economic Literature, 40(2), 402-435.

Fuhrer, J. C. (2000). Habit formation in consumption and its implications formonetary policy models. American Economic Review, 90(3), 367-90.

Graham, C. A. Eggers \& S. Sukhtankar (2004). Does happiness pay? An exploration based on panel data from Russia. Journal of Economic Behavior and Organization, 55, 319-342.

Groves, M.O. (2005). How important is your personality? Labor market returns to personality for women in the US and UK. Journal of Economic Psychology, 26: 827-841 
Ham, R., P.N. Junankar \& R. Wells (2009). Occupational Choice: Personality Matters. IZA Discussion Paper No. 4105.

Heffetz, O., D.J. Benjamin, M.S. Kimball, \& A. Rees-Jones (2012). What Do You Think Would Make You Happier? What Do You Think You Would Choose? American Economic Review, forthcoming.

Heineck, G. \& S. Anger (2010). The returns to cognitive abilities and personality traits in Germany. Labour Economics, 17(3), 535-546.

Helliwell, J.F. \& Huang, H. (2010). How's the job? Well-being and social capital in the workplace'. Industrial and Labor Relations Review, 63(2).

Judge, T., D. Heller \& M.K. Mount (2002). Five-factor model of personality and job satisfaction: A meta-analysis. Journal of Applied Psychology, 87, 530-541.

Kandler, C., W. Bleidorn, R. Riemann, A. Angleitner \& F. Spinath (2012). Life events as environmental states and genetic traits and the role of personality: A longitudinal twin study, Behavior Genetics, 42(1), 57-72.

Lang, F. R., D. John, O. Lüdtke, J. Schupp \& G.G. Wagner (2011). Short assessment of the Big Five: robust across survey methods except telephone interviewing. Behavior Research Methods, 43, 548567.

Larsen, R. \& Z. Prizmic (2008). Regulation of Emotional Well-being: Overcoming the Hedonic Treadmill. In The Science of Subjective Well-Being, M. Eid and R.J. Larsen (Eds.), The Guilford Press, New York.

Lockwood, P. (2002), Could It Happen to You? Predicting the Impact of Downward Comparisons on the Self. Journal of Personality and Social Psychology, 82(3), 343-358.

Luttmer, E. (2005). Neighbours as negatives: Relative earnings and well-being. Quarterly Journal of Economics, 120, 963-1002.

Lyubomirsky, S., \& Ross, L. (1997). Hedonic consequences of social comparison: A contrast of happy and unhappy people. Journal of Personality and Social Psychology, 73, 1141-1157.

Lyubomirsky, S. \& K.L. Tucker (1998). Implications of individual differences in subjective happiness for perceiving, interpreting and thinking about life events. Motivation and emotion, 22, 155-186.

Lyubomirsky, S., K.L. Tucker \& F. Kasri (2001). Responses to hedonically conflicting social comparisons: Comparing happy and unhappy people. European Journal of Social Psychology, 31, 511-535.

McBride, M. (2001). Relative income effects on subjective well-being in the cross-section. Journal of Economic Behavior and Organization, 45, 251-278.

Mohanty, M. S. (2010). Effects of Positive Attitude and Optimism on Employment: Evidence from the US data. Journal of Socio-Economics, 39, 258-270. 
Mueller, G. \& E. Plug (2006). Estimating the Effect of Personality on Male-Female Earnings. Industrial and Labor Relations Review, 60(1), 3-22.

Neumark, D. \& A. Postlewaite (1998). Relative income concerns and the rise in married women's employment. Journal of Public Economics, 70, 157-183.

Nyhus, E.K. \& E. Pons (2005). The effects of personality on earnings. Journal of Economic Psychology, 26, 363-384.

Parducci, A. (1995). Happiness, pleasure, and judgment: the contextual theory and its applications, Erlbaum, Mahwah, NJ.

Powdthavee, N. (2009). How important is rank to individual perception of economic standing? A within-community analysis. Journal of Economic Inequality, 7(3), 225-248.

Roberts, B. W. \& W.F. DelVecchio (2000). The rank-order consistency of personality from childhood to old age: A quantitative review of longitudinal studies. Psychological Bulletin, 126, 3-25.

Roberts, B. W., K. Walton \& W. Viechtbauer (2006). Patterns of mean-level change in personality traits across the life course: A meta-analysis of longitudinal studies. Psychological Bulletin, 132, 125.

Sapolsky, R.M. (2004). Social status and health in humans and other animals. Annual Review of Anthropololy 33, 393-318.

Seidlitz, L., R.S. Wyer \& E. Diener (1997). Cognitive correlates of subjective well-being: The processing of valenced life events by happy and unhappy persons. Journal of Research in Personality, 31, 240-256.

Semykina, A \& S. Linz. (2007). Gender differences in personality and earnings: Evidence from Russia. Journal of Economic Psychology 28(3): 387-410.

Senik, C. (2004). When information dominates comparison: Learning from Russian subjective panel data. Journal of Public Economics, 88(9-10), 2099-2133.

Senik, C. (2005). What Can we Learn from Subjective Data? The Case of Income and Well-Being. Journal of Economic Surveys, 19(1), 43-63.

Senik, C. (2009). Direct evidence on income comparisons and their welfare effects. Journal of Economic Behavior and Organization, 72(1), 408-424.

Soto, C., O. John, S. Gosling \& J.Potter (2011). Age differences in personality traits from 10 to 65: Big Five domains and facets in a large cross-sectional sample. Journal of Personality and Social Psychology, 100, 330-348.

Specht, J., B. Egloff \& S.C. Schmukle (2011). The benefits of believing in chance or fate: External locus of control as a protective factor for coping with the death of a spouse. Social Psychological and Personality Science, 2, 132-137. 
Stutzer, A. \& B. Frey (2006). Does marriage make people happy, or do happy people get married? The Journal of Socio-Economics, 35, 326-347.

Uysal, S. D. \& W. Pohlmeier (2011). Unemployment duration and personality, forthcoming in Journal of Economic Psychology.

van Praag, B.M.S. \& A. Ferrer-i-Carbonell (2008). Happiness Quantified: A Satisfaction Calculus Approach, Oxford University Press. Revised edition.

van Praag, B.M.S. van \& A. Ferrer-i-Carbonell (2010). Happiness Economics: A new Road to Measuring and Comparing Happiness. Foundation and Trends in Microeconomics, 6(1), 1-97.

Van der Zee, K., F. Oldersma, B. Buunk \& D. Bos (1998). Social comparison preferences among cancer patients as related to neuroticism and social comparison orientations. Journal of Personality and Social Psycology, 75, 801-810.

Wagner, G.G., J.R. Frick \& J. Schupp (2007). The German socio-economic panel study SOEP-scope, evolution and enhancements. Schmollers Jahrbuch, 127, 139-169.

Wheeler, L. \& K. Miyake (1992). Social comparison in everyday life. Journal of Personality and Social Psychology, 62, 760-773.

Wood, J. V. \& K. Van der Zee (1997). Social comparisons among cancer patients: Under what conditions are comparisons upward and downward? In B. P. Buunk and F. X. Gibbons (Eds.), Health, coping, and well-being: Perspectives from social comparison theory (pp. 299-328). Hillsdale, NJ: Erlbaum.

Zizzo, D.J (2002). Between utility and cognition: the neurobiology of relative position. Journal of Economic Behavior and Organization, 748, 71-91. 


\section{Tables and figures}

Table 1. Summary statistics - Socioeconomic characteristics

\begin{tabular}{lrr}
\hline & Mean & SD \\
\hline Life satisfaction & 6.960 & 1.752 \\
Household income & 2931.900 & 2060.290 \\
Age & 48.380 & 16.260 \\
Woman & 0.521 & 0.500 \\
Years education & 12.098 & 2.666 \\
No. of adults & 2.179 & 0.841 \\
No. of children & 0.539 & 0.904 \\
Employed & 0.629 & 0.483 \\
Unemployed & 0.073 & 0.259 \\
Inactive & 0.299 & 0.458 \\
Married & 0.663 & 0.473 \\
Single & 0.205 & 0.404 \\
Divorced & 0.072 & 0.258 \\
Widow & 0.061 & 0.239 \\
Badhealth & 0.166 & 0.372 \\
East Germany & 0.257 & 0.437 \\
Foreigner & 0.116 & 0.320 \\
\hline \hline
\end{tabular}

Table 2. Summary statistics - Personality traits

\begin{tabular}{lcr}
\hline \hline & Mean & SD \\
\hline Neuroticism & 3.967 & 1.218 \\
Extraversion & 4.829 & 1.130 \\
Openness & 4.496 & 1.200 \\
Agreeableness & 5.459 & 0.973 \\
Conscientiousness & 5.936 & 0.910 \\
External LOC & 3.545 & 0.878 \\
Positive reciprocity & 5.883 & 0.909 \\
Negative reciprocity & 3.087 & 1.451 \\
\hline \hline
\end{tabular}


Table 3. Rank and personality, FE - German SOEP 2000-2008

\begin{tabular}{|c|c|c|c|c|c|c|c|c|c|c|c|c|c|c|}
\hline & \multirow{2}{*}{\multicolumn{2}{|c|}{ TOTAL SAMPLE }} & \multicolumn{6}{|c|}{ Neuroticism } & \multicolumn{6}{|c|}{ Extraversion } \\
\hline & & & \multicolumn{2}{|c|}{ Top 25\% } & \multirow{2}{*}{$\begin{array}{c}\text { Average } \\
\text { Coeff. } \\
\end{array}$} & \multirow[b]{2}{*}{ t-ratio } & \multicolumn{2}{|c|}{ Bottom $25 \%$} & \multicolumn{2}{|c|}{ Top 25\% } & \multirow{2}{*}{$\begin{array}{r}\text { Average } \\
\text { Coeff. } \\
\end{array}$} & \multirow[b]{2}{*}{ t-ratio } & \multicolumn{2}{|c|}{ Bottom 25\% } \\
\hline & Coeff. & t-ratio & Coeff. & t-ratio & & & Coeff. & t-ratio & Coeff. & t-ratio & & & Coeff. & t-ratio \\
\hline Ln (income) & $0.138^{\text {**** }}$ & 9.84 & $0.103^{* * *}$ & 3.46 & 0.141 & 7.18 & $0.161^{* * *}$ & 5.73 & 0.103 & 3.58 & 0.152 & 7.84 & $0.127^{* * *}$ & 4.33 \\
\hline Rank & $0.070^{* * *}$ & 2.91 & $0.139^{* * *}$ & 2.72 & $0.058 *$ & 1.74 & 0.023 & 0.49 & 0.175 & 3.53 & 0.051 & 1.54 & 0.018 & 0.38 \\
\hline $\begin{array}{l}\text { R-squared } \\
\text { No. of observations }\end{array}$ & $\begin{array}{r}0.013 \\
140572\end{array}$ & & $\begin{array}{r}0.011 \\
35140 \\
\end{array}$ & & $\begin{array}{r}0.015 \\
70280\end{array}$ & & $\begin{array}{r}0.027 \\
35152\end{array}$ & & $\begin{array}{r}0.115 \\
35193\end{array}$ & & $\begin{array}{r}0.010 \\
70238\end{array}$ & & $\begin{array}{r}0.000 \\
35141\end{array}$ & \\
\hline
\end{tabular}

\begin{tabular}{|c|c|c|c|c|c|c|c|c|c|c|c|c|c|}
\hline & \multicolumn{6}{|c|}{ Openness } & \multicolumn{4}{|c|}{ Agreeableness } & \multicolumn{3}{|c|}{ Conscientiousness } \\
\hline & \multicolumn{2}{|l|}{ Tор 25\% } & \multicolumn{2}{|l|}{ Average } & \multicolumn{2}{|c|}{ Bottom 25\% } & \multicolumn{2}{|l|}{ Tор 25\% } & \multirow{2}{*}{$\begin{array}{l}\text { Average } \\
\text { Coeff. }\end{array}$} & Bottom 25\% & Top 25\% & & Bottom 25\% \\
\hline & Coeff. & t-ratio & Coeff. & t-ratio & Coeff. & t-ratio & Coeff. & t-ratio & & Coeff. t-ratio & Coeff. t-ratio & Coeff. t-ratio & Coeff. t-ratio \\
\hline Ln (income) & 0.133 & 4.87 & 0.149 & 7.67 & 0.117 & 3.79 & $0.143^{* * * a}$ & 4.99 & 0.1447 .42 & 0.134 * 4.61 & $0.149^{* * * *} 5.04$ & $0.140 * 6.99$ & $0.121 * * * 45$ \\
\hline Rank & 0.063 & 1.31 & $0.062^{*}$ & 1.87 & $0.092 *$ & 1.82 & 0.117 & 2.35 & $0.021 \quad 0.64$ & $0.104 * 2.16$ & $0.062 \quad 1.23$ & $0.070^{* *} \quad 2.05$ & $0.059 \quad 1.26$ \\
\hline R-squared & 0.020 & & 0.011 & & 0.005 & & 0.010 & & 0.021 & 0.015 & 0.014 & 0.066 & 0.001 \\
\hline \multirow[t]{4}{*}{ No. of observations } & 35268 & & 70061 & & 35243 & & 35209 & & 70161 & 35202 & 35179 & 70251 & 35142 \\
\hline & \multicolumn{6}{|c|}{ External LOC } & \multicolumn{4}{|c|}{ Positive reciprocity } & \multicolumn{3}{|c|}{ Negative reciprocity } \\
\hline & \multicolumn{2}{|c|}{ Top 25\% } & \multicolumn{2}{|c|}{ Average } & \multicolumn{2}{|c|}{ Bottom 25\% } & \multicolumn{2}{|c|}{ Top $25 \%$} & \multirow{2}{*}{$\begin{array}{l}\text { Average } \\
\text { Coeff. t-ratio }\end{array}$} & Bottom $25 \%$ & Top 25\% & Average & Bottom 25\% \\
\hline & Coeff. & t-ratio & Coeff. & t-ratio & Coeff. & t-ratio & Coeff. & t-ratio & & $\begin{array}{cc}\text { Coeff. } & \text { t-ratio } \\
\end{array}$ & Coeff. t-ratio & Coeff. t-ratio & Coeff. t-ratio \\
\hline Ln (income) & 0.261 & 8.44 & $0.122^{* * * * *}$ & 6.06 & 0.067 & 2.53 & 0.128 & 4.54 & $0.132 * 6.70$ & 0.161 * 5.54 & 0.1896 .42 & $0.127 \quad 6.54$ & 0.101 * 3.51 \\
\hline Rank & -0.055 & -1.08 & 0.101 & 2.97 & $0.104 * *$ & 2.24 & $0.092 *$ & 1.86 & $0.069 * 2.05$ & $0.045 \quad 0.93$ & $0.038 \quad 0.77$ & $0.041 \quad 1.23$ & $0.169-3.43$ \\
\hline R-squared & 0.100 & & 0.004 & & 0.017 & & 0.011 & & 0.076 & 0.001 & 0.005 & 0.031 & 0.007 \\
\hline No. of observations & 35196 & & 70173 & & 35203 & & 35162 & & 70223 & 35187 & 35170 & 70201 & 35201 \\
\hline
\end{tabular}

Notes to Table $3:$ i) * denotes significance at the $10 \%$ level, $* *$ denotes significance at the $5 \%$ level, $* * *$ denotes significance at the $1 \%$ level; ii) The results are controlling for age and age squared, years of completed education, household size (number of children and number of adults at home) and additional dummy variables for marital condition, employment status and health condition. Year fixed effects and controls for the 16 German federal states are included as additional regressors. 
Table 4. Testing differences between personality groups.

\begin{tabular}{|c|c|c|c|}
\hline & \multicolumn{3}{|c|}{ t-test } \\
\hline & $\begin{array}{c}\text { top } 25 \% \\
\text { vs. } \\
\text { bottom } 25 \% \\
\end{array}$ & $\begin{array}{c}\text { top } 25 \% \\
\text { vs. } \\
75 \%-25 \% \\
\end{array}$ & $\begin{array}{c}75 \%-25 \% \\
\text { vs. } \\
\text { bottom } 25 \% \\
\end{array}$ \\
\hline Neuroticism & $309.19 * * *$ & $268.99^{* * *}$ & $121.81^{* * *}$ \\
\hline Extraversion & $422.82^{\star * \star}$ & $423.35^{* * \star}$ & $113.48^{\star * \star}$ \\
\hline Openness & $-78.33^{* \star *}$ & $3.60^{* \star *}$ & $-101.67^{\star \star \star}$ \\
\hline Agreebleness & $34.40^{* * *}$ & $39.43^{\star * \star}$ & $-34.21^{\star \star \star}$ \\
\hline Consciousness & $10.40^{* \star *}$ & $-24.90^{\star \star \star}$ & $40.40^{* \star \star}$ \\
\hline External LOC & $-431.32^{* * *}$ & $-516.04^{* \star *}$ & $-12.16^{\star \star \star}$ \\
\hline Positive reciprocity & $126.05^{* * *}$ & $80.32^{* * \star}$ & $80.28^{* * *}$ \\
\hline Negative reciprocity & $-353.32^{\star \star \star}$ & $-11.25^{* * *}$ & $-438.86^{* \star \star}$ \\
\hline
\end{tabular}

Notes to Table 4: i), *** denotes significance at the $1 \%$ level; 
Figure 1.Distribution of personality traits

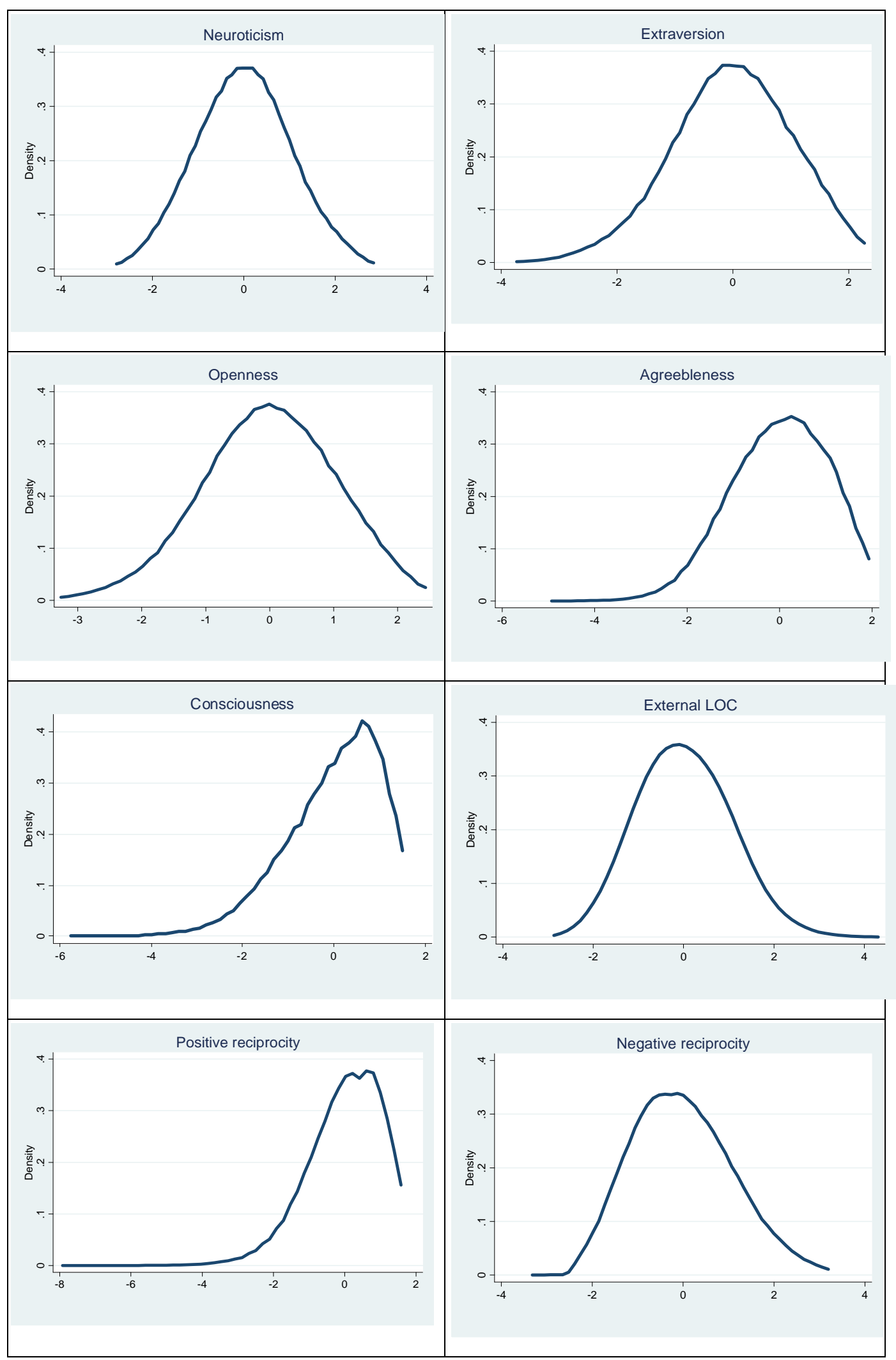

